\title{
Impact of soil fertilizer UGmax on leaf infection degree by leaf spot disease (Cercospora beticola Sacc.) and yield and root quality of sugar beet
}

\section{Wpływ użyźniacza glebowego UGmax na stopień porażenia liści przez chwościka buraka (Cercospora beticola Sacc.) oraz na plon i jakość korzeni buraka cukrowego}

\author{
Dariusz Górski ${ }^{1 *}$, Renata Gaj ${ }^{2}$, Jacek Piszczek ${ }^{1}$, Agnieszka Ulatowska ${ }^{1}$
}

\begin{abstract}
Summary
The studies were conducted in Koniczynka near Torun in 2008-2011. The aim of the studies was an evaluation of soil fertilizer UGmax effect on the degree of leaf infection by leaf spot disease (Cercospora beticola Sacc.), sugar beet yield and roots quality in 2, 3 and 4-year crop rotation. Three experiments with a randomized complete block experimental design with four replications were carried out, one on each crop rotation. Analyses of research results showed that the crop rotation was the main factor determining the degree of leaf infection by $C$. beticola, roots and yield quality. Application of the soil fertilizer UGmax did not have any significant effect.
\end{abstract}

Key words: soil fertilizer; UGmax; sugar beet; Cercospora beticola

\section{Streszczenie}

Badania przeprowadzono w Koniczynce koło Torunia w latach 2008-2011. Oceniano wpływ użyźniacza glebowego UGmax zastosowanego w nawożeniu buraka cukrowego w płodozmianie 2-, 3- i 4-letnim na stopień porażenia roślin przez chwościka buraka Cercospora beticola Sacc. oraz na plon i jakość korzeni. Wykonano trzy doświadczenia, po jednym na każdym płodozmianie, w układzie losowanych bloków w czterech powtórzeniach. Synteza wyników z czterech lat badań wykazała, że płodozmian był głównym czynnikiem determinującym stopień porażenia roślin przez chwościka buraka oraz wielkość plonu korzeni i cukru. Stosowanie użyźniacza glebowego UGmax, niezależnie od wariantu, nie miało istotnego wpływu.

Słowa kluczowe: użyźniacz glebowy; UGmax; burak cukrowy; Cercospora beticola

\footnotetext{
1 Instytut Ochrony Roślin - Państwowy Instytut Badawczy

Terenowa Stacja Doświadczalna

Pigwowa 16, 87-100 Toruń

${ }^{2}$ Uniwersytet Przyrodniczy w Poznaniu

Wydział Rolnictwa i Bioinżynierii

Katedra Chemii Rolnej i Biogeochemii Środowiska

Wojska Polskiego 38/42, 60-625 Poznań

*corresponding author: D.Gorski@iorpib.poznan.pl
} 


\section{Wstęp / Introduction}

Użyźniacz glebowy UGmax jest naturalnym, płynnym koncentratem zawierającym pożyteczne mikroorganizmy (bakterie kwasu mlekowego, bakterie fotosyntetyczne, Azotobacter, Pseudomonas, drożdże, promieniowce) oraz śladowe ilości makroelementów (Truba i wsp. 2012). Według informacji producenta preparat wpływa stymulująco na procesy mineralizacji glebowej materii organicznej oraz transformację jej w próchnicę, zwiększa pulę przyswajalnych składników pokarmowych dla roślin z trudnodostępnych zasobów glebowych. UGmax wpływa także korzystnie na szereg właściwości fizycznych, chemicznych $\mathrm{i}$ biologicznych gleby, w rezultacie podnosi istotnie jej urodzajność oraz kondycję i zdrowotność roślin (http://www. ugmax.pl/). Jednak doniesienia naukowe związane $z$ efektywnością preparatów opartych na tzw. efektywnych mikroorganizmach (EM) nie są jednoznaczne. Część prac dowodzi o braku efektywności tego typu środków (Kucharski i Jastrzębska 2005; Van Vliet i wsp. 2006; Mayer i wsp. 2008; Jakubus i wsp. 2012), inne natomiast potwierdzają ich wysoką efektywność (Sulewska i wsp. 2009; Sosnowski 2011; Zarzecka i Gugała 2013). Biorąc pod uwagę tak dużą rozbieżność wyników badań, pytanie o rzeczywistą efektywność tego typu środków pozostaje ciągle otwarte.

Celem badań była ocena wpływu stosowania użyźniacza glebowego UGmax w uprawie buraka cukrowego w warunkach różnych płodozmianów na stopień porażenia roślin przez chwościka buraka Cercospora beticola oraz na plon i jakość korzeni.

\section{Materiały i metody / Materials and methods}

Badania przeprowadzono w latach 2008-2011 w miejscowości Koniczynka koło Torunia. Doświadczenie założono na glebie średniej, klasy bonitacyjnej IIIb, o składzie mechanicznym gliny piaszczystej (piasek 62,83\%, pył 33,61\%, ił $3,56 \%$ ), odczynie obojętnym $(\mathrm{pH}-7,1)$, zawartości próchnicy $1,57 \%$, zasobności bardzo wysokiej w przyswajalny fosfor $(25 \mathrm{mg} / 100 \mathrm{~g})$, średniej w potas $(18,7 \mathrm{mg} / 100 \mathrm{~g})$ i bardzo wysokiej w magnez (10,4 mg/100 g).

Doświadczenie założono w układzie losowanych bloków w czterech powtórzeniach na trzech różnych płodozmianach: 2-letnim (burak cukrowy, pszenica jara), 3-letnim (burak cukrowy, pszenica jara, pszenica ozima) i 4-letnim (burak cukrowy, pszenica jara, kukurydza, pszenica ozima). Czynnikiem doświadczalnym było zastosowanie użyźniacza glebowego UGmax:

1. Obiekt kontrolny.

2. UGmax $0,3 \mathrm{l} /$ ha stosowany na ściernisko po zbiorze przedplonu (UGmax: 0,3).

3. UGmax $0,61 /$ ha stosowany na ściernisko po zbiorze przedplonu (UGmax: 0,6).

4. UGmax $0,3 \mathrm{l} / \mathrm{ha}$ stosowany na ściernisko po zbiorze przedplonu + UGmax 0,3 1/ha przed siewem buraka (UGmax: 0,3;0,3).

5. UGmax $0,3 \mathrm{l} /$ ha stosowany na ściernisko po zbiorze przedplonu + UGmax 0,3 1/ha przed siewem buraka +
UGmax 0,6 1/ha dolistnie $\mathrm{w}$ stadium $\mathrm{BBCH}$ 14-16)

(UGmax: 0,3; 0,3: 0,6).

Słoma zbóż oraz liście buraka po zbiorach pozostawały na polu. Nawożenie mineralne było takie same na wszystkich płodozmianach. Przed orką zimową stosowano nawozy fosforowo-potasowe w ilości $48 \mathrm{~kg} \mathrm{P}_{2} \mathrm{O}_{5}$ i $128 \mathrm{~kg} \mathrm{~K}_{2} \mathrm{O}$ na ha $\mathrm{w}$ postaci Polifoski $4\left(4 \% \mathrm{~N}, 12 \% \mathrm{P}_{2} \mathrm{O}_{5}, 32 \% \mathrm{~K}_{2} \mathrm{O}\right.$, $\left.2 \% \quad \mathrm{MgO}, \quad 9 \% \quad \mathrm{SO}_{3}\right)$. Nawożenie azotem stosowano w dwóch dawkach: $60 \mathrm{~kg} \mathrm{~N} / \mathrm{ha}$ dwa tygodnie przed siewem buraka cukrowego $\mathrm{w}$ postaci saletrzaku $\mathrm{z}$ borem $(27 \% \mathrm{~N}, 2 \% \mathrm{CaO}, 4 \% \mathrm{MgO}, 0,2 \% \mathrm{~B})$ oraz $60 \mathrm{~kg} \mathrm{~N} / \mathrm{ha}$ w fazie 3-4 par liści właściwych (BBCH 13/14) w postaci saletry amonowej (34\% N).

Pod koniec wegetacji oznaczono stopień porażenia roślin przez chwościka buraka oraz plon i jakość korzeni. Ocenę porażenia roślin przez chwościka buraka wykonano według normy EPPO PP 1/1(4) w skali 9-stopniowej, gdzie 9 - oznacza roślinę wolną od objawów choroby, a 1 roślinę o liściach zniszczonych w ponad $60 \%$. Plon korzeni buraka cukrowego odmiany Soplica oznaczono na podstawie roślin zebranych ręcznie $\mathrm{z}$ każdego poletka $\mathrm{z}$ powierzchni $10 \mathrm{~m}^{2}$. Z każdego poletka pobrano losowo próby 24 korzeni, w których oznaczono zawartość cukru, potasu, sodu i azotu alfa-aminowego. Analizę wykonano na automatycznej linii Venema w laboratorium Kutnowskiej Hodowli Buraka Cukrowego w Straszkowie. Plon technologiczny cukru obliczono według formuły Reinefelda (Stępień i wsp. 2010).

Wyniki opracowano statystycznie przy pomocy analizy wariancji dla jednoczynnikowego układu losowanych bloków niezależnie dla każdego płodozmianu. W syntezie wyników lata badań potraktowano jako efekt losowy. Istotność różnic między średnimi sprawdzano przy pomoc testu Tukeya na poziomie istotności $\mathrm{p}=0,05$. W celu oceny wpływu płodozmianu na analizowane cechy przeprowadzono analizę kontrastów, w której płodozmiany 2- i 3-letni porównano z płodozmianem 4-letnim. W obliczeniach płodozmian potraktowano jako czynnik doświadczalny o trzech poziomach i 20 powtórzeniach. Całość obliczeń wykonano w programie ARM® 9 (Agricultural Research Manager) z dodatkiem ARM ST8 (Summary Across Trials) oraz STATISTICA v. 10.

\section{Wyniki i dyskusja / Results and discussion}

W literaturze przedmiotu spotyka się skrajnie rozbieżne stanowiska na temat wpływu środków opartych na tzw. efektywnych mikroorganizmach na zdrowotność roślin oraz wysokość i jakość plonów. Kucharski i Jastrzębska (2005) nie stwierdzili pozytywnego wpływu stosowania preparatów EM1 i EM2 w uprawie sałaty. Autorzy wykazali negatywny wpływ aplikacji tych środków na wzrost i rozwój sałaty lodowej, namnażanie bakterii oligotroficznych, przetrwalników bakterii kopiotroficznych, promieniowców, wolnożyjących bakterii wiążących azot (Azotobacter spp.) oraz grzybów. Van Vliet i wsp. (2006) w badaniach przeprowadzonych w Holandii nie stwierdzili istotnych zmian w składzie chemicznym kompostu po zastosowaniu EM i sześciotygodniowej inkubacji nawozu organicznego $\mathrm{W}$ temperaturze $20^{\circ} \mathrm{C}$. Autorzy 
odnotowali również duże różnice w zawartości DNA bakteryjnego preparatów tej samej serii, co świadczy o niskiej powtarzalności składu mikrobiologicznego testowanego produktu. Mayer i wsp. (2008) w czteroletnim doświadczeniu polowym przeprowadzonym w Szwajcarii wykazali, że stosowanie EM nie miało istotnego wpływu na plony badanych roślin (ziemniak, jęczmień ozimy, pszenica ozima, lucerna) ani na właściwości mikrobiologiczne gleby. Jakubus i wsp. (2008) w badaniach nad wpływem stosowania EM na właściwości fizykochemiczne gleby, nie zaobserwowali istotnego ich wpływu na: zawartość węgla organicznego, próchnicy glebowej, azotu ogólnego, azotu mineralnego oraz dostępność przyswajalnych form makro- i mikroelementów. Autorzy podkreślają, że wartość ocenianych cech zależała głównie od rodzaju i dawki pożywki (polisacharydu) dodanego do gleby, a nie od badanych środków.

Odmienne wyniki odnotowali Trawczyński i Bogdanowicz (2007), którzy wykazali istotny wpływ stosowania środka UGmax na plon bulw ziemniaka, zawartość suchej masy oraz wzrost zawartości próchnicy i przyswajalnego fosforu w glebie. Zarzecka i Gugała (2013) stwierdzili, że stosowanie środka UGmax skutkowało wzrostem plonu ogólnego i plonu dużych bulw ziemniaka średnio o 27,2 i $35,3 \%$ w porównaniu do obiektu kontrolnego. Sulewska i wsp. (2009) w trzyletnich badaniach polowych nad wpływem środka UGmax na plonowanie kukurydzy uprawianej w 6-letniej monokulturze, po zastosowaniu preparatu, obserwowali istotny wzrost plonu ziarna $(9,4 \%)$ oraz suchej masy roślin (32,3\%). Natomiast Sosnowski (2011) zanotował istotny wzrost respiracji $\mathrm{CO}_{2}$ (średnio o 26\%) przez glebę, na której uprawiano mieszanki motylkowo- trawiaste i stosowano rocznie 0,9 1/ha użyźniacza glebowego (UG). Wzrost emisji gazu według autora świadczy o intensyfikacji procesów mineralizacji glebowych substancji organicznych na skutek zastosowania preparatu.

Condor i wsp. (2007) oraz Martyniuk (2011) w pracach przeglądowych dokonali krytycznej oceny wielu prac, w których wykazano wysoką efektywność preparatów opartych na efektywnych mikroorganizmach. Autorzy stwierdzili, że nie ma cenionych publikacji indeksowanych, które potwierdzałyby ich wysoką efektywność. Ponadto badacze uważają, że wiele prac donoszących o pozytywnym działaniu tego typu preparatów zawiera poważne błędy metodyczne, które podważają wiarygodność wyników. W podsumowaniu autorzy konkludują, że w dalszej perspektywie brak rzetelnej wiedzy o efektywności EM może przyczynić się do degradacji gleby na skutek zaniechania właściwych działań mogących przynieść pożądane efekty, takich jak: nawożenie organiczne, uprawa międzyplonów, właściwy płodozmian czy zbilansowane nawożenie mineralne.

Badania własne wykazały, że nawożenie środkiem UGmax, niezależnie od wariantu, nie miało istotnego wpływu na stopień porażenia roślin przez chwościk buraka, plon korzeni, zawartość cukru w korzeniach oraz plon technologiczny cukru (tab. 1-4). Jednak w latach 2008 i 2010 zaobserwowano tendencję do zwiększania plonu korzeni buraka w płodozmianie 3- i 4-letnim pod wpływem stosowania UGmax. Głównym czynnikiem oddziałującym istotnie na zmienność wyników był płodozmian oraz warunki pogodowe w latach badań (tab. 5).

Tabela 1. Wpływ nawożenia użyźniaczem glebowym UGmax na stopień porażenia liści przez chwościka buraka w różnych warunkach uprawy

Table 1. Effect of the soil fertilizer UGmax on the degree of plant infection by leaf spot disease (C. beticola) in different cultivation conditions

\begin{tabular}{|c|c|c|c|c|c|c|}
\hline \multirow{2}{*}{$\begin{array}{l}\mathrm{Nr} \\
\text { No. }\end{array}$} & \multirow{2}{*}{ Czynnik - Factor $[\mathrm{A}]$} & \multicolumn{5}{|c|}{ Rok - Year [L] } \\
\hline & & 2008 & 2009 & 2010 & 2011 & 2008-2011 \\
\hline 1 & 2 & 3 & 4 & 5 & 6 & 7 \\
\hline \multicolumn{7}{|c|}{ Płodozmian 2-letni-2-year crop rotation } \\
\hline 1 & kontrola - control & $6,8 \mathrm{a}$ & $5,0 \mathrm{a}$ & $6,3 \mathrm{a}$ & $7,0 \mathrm{a}$ & $6,3 \mathrm{a}$ \\
\hline 2 & UGmax: 0,3 (1/ha) & $6,8 \mathrm{a}$ & $5,0 \mathrm{a}$ & $6,3 \mathrm{a}$ & $7,0 \mathrm{a}$ & $6,3 \mathrm{a}$ \\
\hline 3 & UGmax: 0,6 (1/ha) & $6,8 \mathrm{a}$ & $5,0 \mathrm{a}$ & $6,0 \mathrm{a}$ & $7,5 \mathrm{a}$ & $6,3 \mathrm{a}$ \\
\hline 4 & UGmax: $0,3+0,3$ (1/ha) & $6,8 \mathrm{a}$ & $5,3 \mathrm{a}$ & $6,0 \mathrm{a}$ & $7,3 \mathrm{a}$ & $6,3 \mathrm{a}$ \\
\hline 5 & UGmax: $0,3+0,3+0,6(1 / \mathrm{ha})$ & $6,5 \mathrm{a}$ & $5,0 \mathrm{a}$ & $6,3 \mathrm{a}$ & $7,5 \mathrm{a}$ & $6,3 \mathrm{a}$ \\
\hline \multicolumn{2}{|c|}{ Średnia-Mean } & 6,7 & 5,1 & 6,2 & 7,3 & 6,3 \\
\hline \multicolumn{2}{|c|}{$\operatorname{NIR}(0,05)-\operatorname{LSD}(0.05)$} & 0,97 & 0,5 & 1,32 & 1,13 & 0,4 \\
\hline \multicolumn{2}{|c|}{ Interakcja - Interaction $[\mathrm{L} \times \mathrm{A}]$} & - & - & - & - & i.n. \\
\hline \multicolumn{7}{|c|}{ Płodozmian 3-letni-3-year crop rotation } \\
\hline 1 & kontrola - control & $5,5 \mathrm{a}$ & $5,3 \mathrm{a}$ & $6,5 \mathrm{a}$ & $7,3 \mathrm{a}$ & $6,1 \mathrm{a}$ \\
\hline 2 & UGmax: 0,3 (1/ha) & $5,0 \mathrm{a}$ & $5,5 \mathrm{a}$ & $6,5 \mathrm{a}$ & $7,3 \mathrm{a}$ & $6,1 \mathrm{a}$ \\
\hline 3 & UGmax: 0,6 (1/ha) & $5,5 \mathrm{a}$ & $5,0 \mathrm{a}$ & $6,5 \mathrm{a}$ & $7,0 \mathrm{a}$ & $6,0 \mathrm{a}$ \\
\hline 4 & UGmax: $0,3+0,3$ (1/ha) & $5,5 \mathrm{a}$ & $5,0 \mathrm{a}$ & $6,5 \mathrm{a}$ & $7,0 \mathrm{a}$ & $6,0 \mathrm{a}$ \\
\hline 5 & UGmax: $0,3+0,3+0,6(1 / \mathrm{ha})$ & $5,5 \mathrm{a}$ & $5,0 \mathrm{a}$ & $6,8 \mathrm{a}$ & $7,0 \mathrm{a}$ & $6,1 \mathrm{a}$ \\
\hline \multicolumn{2}{|c|}{ Średnia - Mean } & 5,4 & 5,2 & 6,6 & 7,1 & 6,1 \\
\hline
\end{tabular}




\begin{tabular}{|c|c|c|c|c|c|c|}
\hline \multicolumn{2}{|c|}{1} & 2 & 3 & 4 & 5 & 6 \\
\hline \multicolumn{2}{|c|}{$\operatorname{NIR}(0,05)-\operatorname{LSD}(0.05)$} & 0,6 & 0,8 & 1,3 & 1,4 & 0,4 \\
\hline \multicolumn{2}{|c|}{ Interakcja - Interaction $[\mathrm{L} \times \mathrm{A}]$} & - & - & - & - & i.n. \\
\hline \multicolumn{7}{|c|}{ Płodozmian 4-letni - 4-year crop rotation } \\
\hline 1 & kontrola - control & $6,5 \mathrm{a}$ & $5,0 \mathrm{a}$ & $7,8 \mathrm{a}$ & $7,8 \mathrm{a}$ & $6,8 \mathrm{a}$ \\
\hline 2 & UGmax: 0,3 (1/ha) & $6,8 \mathrm{a}$ & $5,0 \mathrm{a}$ & $7,8 \mathrm{a}$ & $7,5 \mathrm{a}$ & $6,8 \mathrm{a}$ \\
\hline 3 & UGmax: 0,6 (1/ha) & $7,0 \mathrm{a}$ & $5,0 \mathrm{a}$ & $7,3 \mathrm{a}$ & $7,5 \mathrm{a}$ & $6,7 \mathrm{a}$ \\
\hline 4 & UGmax: $0,3+0,3$ (1/ha) & $6,8 \mathrm{a}$ & $5,0 \mathrm{a}$ & $8,3 \mathrm{a}$ & $7,8 \mathrm{a}$ & $6,9 \mathrm{a}$ \\
\hline 5 & UGmax: $0,3+0,3+0,6(1 / \mathrm{ha})$ & $7,0 \mathrm{a}$ & $5,0 \mathrm{a}$ & $7,5 \mathrm{a}$ & $7,8 \mathrm{a}$ & $6,8 \mathrm{a}$ \\
\hline \multicolumn{2}{|c|}{ Średnia - Mean } & 6,8 & 5,0 & 7,7 & 7,7 & 6,8 \\
\hline \multicolumn{2}{|c|}{$\operatorname{NIR}(0,05)-\operatorname{LSD}(0.05)$} & 0,7 & 0,3 & 2,1 & 0,7 & 0,5 \\
\hline \multicolumn{2}{|c|}{ Interakcja - Interaction $[\mathrm{L} \times \mathrm{A}]$} & - & - & - & - & i.n. \\
\hline
\end{tabular}

i.n. - interakcja nieistotna - interaction not significant

Średnie w kolumnach oznaczone tymi samymi literami nie różnią się istotnie (test Tukeya, $\mathrm{p}=0,05$ ) - Means in columns followed by the same letter do not significantly differ (Tukey's test, $\mathrm{p}=0.05$ )

Tabela 2. Wpływ nawożenia użyźniaczem glebowym UGmax na plon korzeni buraka cukrowego w różnych warunkach uprawy Table 2. Effect of the soil fertilizer UGmax on root yield in different cultivation conditions

\begin{tabular}{|c|c|c|c|c|c|c|}
\hline \multirow{2}{*}{$\begin{array}{l}\mathrm{Nr} \\
\text { No. }\end{array}$} & \multirow{2}{*}{ Czynnik - Factor [A] } & \multicolumn{5}{|c|}{ Rok - Year [L] } \\
\hline & & 2008 & 2009 & 2010 & 2011 & $2008-2011$ \\
\hline \multicolumn{7}{|c|}{ Płodozmian 2-letni-2-year crop rotation } \\
\hline 1 & kontrola - control & $51,34 \mathrm{a}$ & $40,41 \mathrm{a}$ & 52,24 a & $49,26 \mathrm{a}$ & $48,31 \mathrm{a}$ \\
\hline 2 & UGmax: 0,3 (1/ha) & $50,83 \mathrm{a}$ & $37,94 \mathrm{a}$ & $48,89 \mathrm{a}$ & $44,13 \mathrm{a}$ & $45,45 \mathrm{a}$ \\
\hline 3 & UGmax: 0,6 (1/ha) & $49,54 \mathrm{a}$ & $40,02 \mathrm{a}$ & $51,88 \mathrm{a}$ & $50,22 \mathrm{a}$ & $47,91 \mathrm{a}$ \\
\hline 4 & UGmax: $0,3+0,3(1 / h a)$ & $54,42 \mathrm{a}$ & $38,42 \mathrm{a}$ & $47,10 \mathrm{a}$ & $48,32 \mathrm{a}$ & $47,06 \mathrm{a}$ \\
\hline 5 & UGmax: $0,3+0,3+0,6$ & $53,58 \mathrm{a}$ & $39,46 \mathrm{a}$ & $46,08 \mathrm{a}$ & $47,22 \mathrm{a}$ & $46,58 \mathrm{a}$ \\
\hline \multicolumn{2}{|c|}{ Średnia - Mean } & 51,94 & 39,25 & 49,24 & 47,83 & 47,06 \\
\hline \multicolumn{2}{|c|}{$\operatorname{NIR}(0,05)-\operatorname{LSD}(0.05)$} & 7,37 & 4,81 & 6,53 & 7,70 & 4,21 \\
\hline \multicolumn{2}{|c|}{ Interakcja - Interaction $[\mathrm{L} \times \mathrm{A}]$} & - & - & - & - & i.i. \\
\hline
\end{tabular}

Płodozmian 3-letni - 3-year crop rotation

\begin{tabular}{|c|c|c|c|c|c|c|}
\hline 1 & kontrola - control & $40,76 \mathrm{~b}$ & $71,71 \mathrm{a}$ & $45,46 \mathrm{a}$ & $62,02 \mathrm{a}$ & $54,99 \mathrm{a}$ \\
\hline 2 & UGmax: 0,3 (1/ha) & $45,98 \mathrm{ab}$ & 68,76 a & $50,40 \mathrm{a}$ & $63,65 \mathrm{a}$ & $57,20 \mathrm{a}$ \\
\hline 3 & UGmax: 0,6 (1/ha) & $49,33 \mathrm{a}$ & $71,74 \mathrm{a}$ & $47,75 \mathrm{a}$ & $57,64 \mathrm{a}$ & $56,61 \mathrm{a}$ \\
\hline 4 & UGmax: $0,3+0,3(1 /$ ha $)$ & $43,96 \mathrm{ab}$ & $67,79 \mathrm{a}$ & $49,35 \mathrm{a}$ & $57,82 \mathrm{a}$ & $54,73 \mathrm{a}$ \\
\hline 5 & UGmax: $0,3+0,3+0,6(1 / \mathrm{ha})$ & $45,86 \mathrm{ab}$ & $67,96 \mathrm{a}$ & $50,73 \mathrm{a}$ & $58,99 \mathrm{a}$ & $55,88 \mathrm{a}$ \\
\hline \multicolumn{2}{|c|}{ Średnia - Mean } & 45,18 & 69,59 & 48,73 & 60,02 & 55,88 \\
\hline \multicolumn{2}{|c|}{$\operatorname{NIR}(0,05)-\operatorname{LSD}(0.05)$} & 7,57 & 12,69 & 9,42 & 9,06 & 5,35 \\
\hline \multicolumn{2}{|c|}{ Interakcja - Interaction $[\mathrm{L} \times \mathrm{A}]$} & - & - & - & - & i.n. \\
\hline \multicolumn{7}{|c|}{ Płodozmian 4-letni - 4-year crop rotation } \\
\hline 1 & kontrola - control & $60,74 \mathrm{c}$ & $71,22 \mathrm{a}$ & $63,19 \mathrm{a}$ & $62,47 \mathrm{a}$ & $64,40 \mathrm{a}$ \\
\hline 2 & UGmax: 0,3 (1/ha) & $75,14 b$ & $72,39 \mathrm{a}$ & $67,82 \mathrm{a}$ & $61,78 \mathrm{a}$ & $69,28 \mathrm{a}$ \\
\hline 3 & UGmax: 0,6 (1/ha) & $83,61 \mathrm{a}$ & $74,69 \mathrm{a}$ & $65,01 \mathrm{a}$ & $63,22 \mathrm{a}$ & $71,63 \mathrm{a}$ \\
\hline 4 & UGmax: $0,3+0,3$ (1/ha) & $71,75 \mathrm{~b}$ & $69,07 \mathrm{a}$ & $65,77 \mathrm{a}$ & $62,12 \mathrm{a}$ & $67,18 \mathrm{a}$ \\
\hline 5 & UGmax: $0,3+0,3+0,6(1 / \mathrm{ha})$ & $75,80 \mathrm{~b}$ & $70,60 \mathrm{a}$ & $65,15 \mathrm{a}$ & $66,54 \mathrm{a}$ & $69,52 \mathrm{a}$ \\
\hline \multicolumn{2}{|c|}{ Średnia - Mean } & 73,41 & 71,59 & 65,39 & 63,22 & 68,40 \\
\hline \multicolumn{2}{|c|}{$\operatorname{NIR}(0,05)-\operatorname{LSD}(0.05)$} & 7,70 & 12,57 & 8,66 & 7,28 & 8,20 \\
\hline \multicolumn{2}{|c|}{ Interakcja - Interaction $[\mathrm{L} \times \mathrm{A}]$} & - & - & - & - & i.i. \\
\hline
\end{tabular}

i.n. - interakcja nieistotna - interaction not significant; i.i. - interakcja istotna - interaction significant

Średnie w kolumnach oznaczone tymi samymi literami nie różnią się istotnie (test Tukeya, p=0,05) - Means in columns followed by the same letter do not significantly differ (Tukey’s test, $\mathrm{p}=0.05$ ) 
Tabela 3. Wpływ nawożenia użyźniaczem glebowym UGmax na zawartość cukru w korzeniach w różnych warunkach uprawy

Table 3. Effect of the soil fertilizer UGmax on sugar content in root in different cultivation conditions

\begin{tabular}{|c|c|c|c|c|c|c|}
\hline \multirow{2}{*}{$\begin{array}{l}\mathrm{Nr} \\
\text { No. }\end{array}$} & \multirow{2}{*}{ Czynnik - Factor $[\mathrm{A}]$} & \multicolumn{5}{|c|}{ Rok - Year [L] } \\
\hline & & 2008 & 2009 & 2010 & 2011 & $2008-2011$ \\
\hline \multicolumn{7}{|c|}{ Płodozmian 2-letni - 2-year crop rotation } \\
\hline 1 & kontrola - control & $17,28 \mathrm{a}$ & $16,86 \mathrm{a}$ & $15,72 \mathrm{a}$ & $17,45 \mathrm{a}$ & $16,83 \mathrm{a}$ \\
\hline 2 & UGmax: 0,3 (1/ha) & $17,21 \mathrm{a}$ & $16,96 \mathrm{a}$ & $16,50 \mathrm{a}$ & $17,43 \mathrm{a}$ & $17,03 \mathrm{a}$ \\
\hline 3 & UGmax: 0,6 (1/ha) & $17,54 \mathrm{a}$ & $16,79 \mathrm{a}$ & $16,56 \mathrm{a}$ & $17,25 \mathrm{a}$ & $17,03 \mathrm{a}$ \\
\hline 4 & UGmax: $0,3+0,3(1 /$ ha $)$ & 17,36 a & $17,15 \mathrm{a}$ & $15,94 \mathrm{a}$ & $17,43 \mathrm{a}$ & $16,97 \mathrm{a}$ \\
\hline 5 & UGmax: $0,3+0,3+0,6(1 / \mathrm{ha})$ & $17,50 \mathrm{a}$ & $16,84 \mathrm{a}$ & $16,01 \mathrm{a}$ & $17,55 \mathrm{a}$ & $16,98 \mathrm{a}$ \\
\hline \multicolumn{2}{|c|}{ Średnia - Mean } & 17,38 & 16,92 & 16,15 & 17,42 & 16,97 \\
\hline \multicolumn{2}{|c|}{$\operatorname{NIR}(0,05)-\operatorname{LSD}(0.05)$} & 0,99 & 0,51 & 0,92 & 0,54 & 0,46 \\
\hline \multicolumn{2}{|c|}{ Interakcja - Interaction $[\mathrm{L} \times \mathrm{A}]$} & - & - & - & - & i.n. \\
\hline
\end{tabular}

Interakcja - Interaction $[\mathrm{L} \times \mathrm{A}]$

Płodozmian 3-letni - 3-year crop rotation

\begin{tabular}{|c|c|c|c|c|c|c|}
\hline 1 & kontrola - control & $17,45 \mathrm{a}$ & $17,74 \mathrm{a}$ & $16,56 \mathrm{a}$ & $16,63 \mathrm{a}$ & $17,09 \mathrm{a}$ \\
\hline 2 & UGmax: 0,3 (1/ha) & $17,56 \mathrm{a}$ & $17,43 \mathrm{a}$ & $16,89 \mathrm{a}$ & $16,75 \mathrm{a}$ & $17,16 \mathrm{a}$ \\
\hline 3 & UGmax: 0,6 (1/ha) & $17,54 \mathrm{a}$ & $17,51 \mathrm{a}$ & $16,45 \mathrm{a}$ & $16,71 \mathrm{a}$ & $17,05 \mathrm{a}$ \\
\hline 4 & UGmax: $0,3+0,3(1 / h a)$ & $17,57 \mathrm{a}$ & $17,36 \mathrm{a}$ & $16,49 \mathrm{a}$ & $16,77 \mathrm{a}$ & $17,05 \mathrm{a}$ \\
\hline 5 & UGmax: $0,3+0,3+0,6(1 / \mathrm{ha})$ & $17,62 \mathrm{a}$ & $17,73 \mathrm{a}$ & $16,81 \mathrm{a}$ & $16,37 \mathrm{a}$ & $17,13 \mathrm{a}$ \\
\hline \multicolumn{2}{|c|}{ Średnia-Mean } & 17,55 & 17,55 & 16,64 & 16,65 & 17,10 \\
\hline \multicolumn{2}{|c|}{$\operatorname{NIR}(0,05)-\operatorname{LSD}(0.05)$} & 0,61 & 0,54 & 0,99 & 0,51 & 0,35 \\
\hline \multicolumn{2}{|c|}{ Interakcja - Interaction $[\mathrm{L} \times \mathrm{A}]$} & - & - & - & - & i.n. \\
\hline \multicolumn{7}{|c|}{ Płodozmian 4-letni - 4-year crop rotation } \\
\hline 1 & kontrola - control & 17,67 a & $17,41 \mathrm{a}$ & $16,22 \mathrm{a}$ & $16,73 \mathrm{a}$ & $17,01 \mathrm{a}$ \\
\hline 2 & UGmax: 0,3 (1/ha) & $17,44 \mathrm{a}$ & $17,35 \mathrm{a}$ & $15,78 \mathrm{ab}$ & $17,27 \mathrm{a}$ & $16,96 \mathrm{a}$ \\
\hline 3 & UGmax: 0,6 (1/ha) & $17,40 \mathrm{a}$ & $17,26 \mathrm{a}$ & $15,78 \mathrm{ab}$ & $16,97 \mathrm{a}$ & $16,85 \mathrm{a}$ \\
\hline 4 & UGmax: $0,3+0,3(1 /$ ha $)$ & $17,96 \mathrm{a}$ & $17,39 \mathrm{a}$ & $15,81 \mathrm{ab}$ & 17,19 a & $17,09 \mathrm{a}$ \\
\hline 5 & UGmax: $0,3+0,3+0,6(1 / h a)$ & 17,67 a & $17,39 \mathrm{a}$ & $15,53 \mathrm{~b}$ & $17,07 \mathrm{a}$ & $16,91 \mathrm{a}$ \\
\hline \multicolumn{2}{|c|}{ Średnia - Mean } & 17,63 & 17,36 & 15,82 & 17,05 & 16,96 \\
\hline \multicolumn{2}{|c|}{$\operatorname{NIR}(0,05)-\operatorname{LSD}(0.05)$} & 1,04 & 0,70 & 0,55 & 0,69 & 0,42 \\
\hline \multicolumn{2}{|c|}{ Interakcja - Interaction $[\mathrm{L} \times \mathrm{A}]$} & - & - & - & - & i.n. \\
\hline
\end{tabular}

i.n. - interakcja nieistotna - interaction not significant

Średnie w kolumnach oznaczone tymi samymi literami nie różnią się istotnie (test Tukeya, $\mathrm{p}=0,05$ ) - Means in columns followed by same letter do not significantly differ (Tukey test, $\mathrm{p}=0.05$ )

Tabela 4. Wpływ nawożenia użyźniaczem glebowym UGmax na plon technologiczny cukru w różnych warunkach uprawy

Table 4. Effect of the soil fertilizer UGmax on sugar yield in different cultivation conditions

\begin{tabular}{|c|c|c|c|c|c|c|}
\hline \multirow{2}{*}{$\begin{array}{c}\mathrm{Nr} \\
\text { No. }\end{array}$} & \multirow{2}{*}{ Czynnik - Factor [A] } & \multicolumn{5}{|c|}{ Rok - Year $[\mathrm{L}]$} \\
\hline & & 2008 & 2009 & 2010 & 2011 & $2008-2011$ \\
\hline 1 & 2 & 3 & 4 & 5 & 6 & 7 \\
\hline \multicolumn{7}{|c|}{ Płodozmian 2-letni-2-year crop rotation } \\
\hline 1 & kontrola - control & $7,96 \mathrm{a}$ & $6,15 \mathrm{a}$ & $7,64 \mathrm{ab}$ & $8,00 \mathrm{a}$ & $7,44 \mathrm{a}$ \\
\hline 2 & UGmax: 0,3 (1/ha) & $7,81 \mathrm{a}$ & $5,83 \mathrm{a}$ & $7,57 \mathrm{ab}$ & $7,23 \mathrm{a}$ & $7,11 \mathrm{a}$ \\
\hline 3 & UGmax: 0,6 (1/ha) & $7,83 \mathrm{a}$ & $6,08 \mathrm{a}$ & $8,04 \mathrm{a}$ & $8,15 \mathrm{a}$ & $7,53 \mathrm{a}$ \\
\hline 4 & UGmax: $0,3+0,3$ (1/ha) & $8,46 \mathrm{a}$ & $5,96 \mathrm{a}$ & $6,97 \mathrm{ab}$ & $7,90 \mathrm{a}$ & $7,32 \mathrm{a}$ \\
\hline 5 & UGmax: $0,3+0,3+0,6(1 /$ ha $)$ & $8,40 \mathrm{a}$ & $6,01 \mathrm{a}$ & $6,83 \mathrm{~b}$ & $7,78 \mathrm{a}$ & $7,25 \mathrm{a}$ \\
\hline \multicolumn{2}{|c|}{ Średnia - Mean } & 8,09 & 6,01 & 7,41 & 7,81 & 7,33 \\
\hline \multicolumn{2}{|c|}{$\operatorname{NIR}(0,05)-\operatorname{LSD}(0.05)$} & 1,38 & 0,74 & 1,12 & 1,45 & 0,72 \\
\hline \multicolumn{2}{|c|}{ Interakcja - Interaction $[\mathrm{L} \times \mathrm{A}]$} & - & - & - & - & i.n. \\
\hline
\end{tabular}




\begin{tabular}{|c|c|c|c|c|c|c|}
\hline & 1 & 2 & 3 & 4 & 5 & 6 \\
\hline \multicolumn{7}{|c|}{ Płodozmian 3-letni - 3-year crop rotation } \\
\hline 1 & kontrola - control & $6,41 \mathrm{~b}$ & $11,51 \mathrm{a}$ & $7,01 \mathrm{a}$ & $9,59 \mathrm{a}$ & $8,63 \mathrm{a}$ \\
\hline 2 & UGmax: $0,3(1 / \mathrm{ha})$ & $7,24 \mathrm{ab}$ & $10,82 \mathrm{a}$ & $7,97 \mathrm{a}$ & $9,91 \mathrm{a}$ & $8,98 \mathrm{a}$ \\
\hline 3 & UGmax: 0,6 (1/ha) & 7,79 a & $11,35 \mathrm{a}$ & $7,30 \mathrm{a}$ & $8,90 \mathrm{a}$ & $8,83 \mathrm{a}$ \\
\hline 4 & UGmax: $0,3+0,3(1 /$ ha $)$ & $6,94 \mathrm{ab}$ & $10,61 \mathrm{a}$ & $7,57 \mathrm{a}$ & $9,00 \mathrm{a}$ & $8,53 \mathrm{a}$ \\
\hline 5 & UGmax: $0,3+0,3+0,6(1 / h a)$ & $7,27 \mathrm{ab}$ & $10,91 \mathrm{a}$ & $7,92 \mathrm{a}$ & $8,97 \mathrm{a}$ & $8,77 \mathrm{a}$ \\
\hline \multicolumn{2}{|c|}{ Średnia - Mean } & 7,13 & 11,04 & 7,56 & 9,27 & 8,75 \\
\hline \multicolumn{2}{|c|}{$\operatorname{NIR}(0,05)-\operatorname{LSD}(0.05)$} & 1,29 & 2,28 & 1,61 & 1,29 & 0,93 \\
\hline \multicolumn{2}{|c|}{ Interakcja - Interaction $[\mathrm{L} \times \mathrm{A}]$} & - & - & - & - & i.n. \\
\hline \multicolumn{7}{|c|}{ Płodozmian 4-letni - 4-year crop rotation } \\
\hline 1 & kontrola - control & $9,60 \mathrm{~b}$ & $10,91 \mathrm{a}$ & $9,66 \mathrm{a}$ & $9,63 \mathrm{a}$ & $9,95 \mathrm{a}$ \\
\hline 2 & UGmax: 0,3 (1/ha) & $11,61 \mathrm{a}$ & $11,05 \mathrm{a}$ & $9,92 \mathrm{a}$ & $9,92 \mathrm{a}$ & $10,63 \mathrm{a}$ \\
\hline 3 & UGmax: 0,6 (1/ha) & $12,86 \mathrm{a}$ & $11,25 \mathrm{a}$ & $9,57 \mathrm{a}$ & $9,84 \mathrm{a}$ & $10,88 \mathrm{a}$ \\
\hline 4 & UGmax: $0,3+0,3(1 /$ ha $)$ & $11,38 \mathrm{a}$ & $10,66 \mathrm{a}$ & $9,63 \mathrm{a}$ & $9,86 \mathrm{a}$ & $10,38 \mathrm{a}$ \\
\hline 5 & UGmax: $0,3+0,3+0,6(1 / \mathrm{ha})$ & $11,90 \mathrm{a}$ & $10,79 \mathrm{a}$ & $9,41 \mathrm{a}$ & $10,49 \mathrm{a}$ & $10,64 \mathrm{a}$ \\
\hline \multicolumn{2}{|c|}{ Średnia-Mean } & 11,47 & 10,93 & 9,64 & 9,95 & 10,50 \\
\hline \multicolumn{2}{|c|}{$\operatorname{NIR}(0,05)-\operatorname{LSD}(0.05)$} & 1,76 & 2,18 & 1,18 & 1,36 & 1,22 \\
\hline \multicolumn{2}{|c|}{ Interakcja - Interaction $[\mathrm{L} \times \mathrm{A}]$} & - & - & - & - & i.i. \\
\hline
\end{tabular}

i.n. - interakcja nieistotna - interaction not significant; i.i. - interakcja istotna - interaction significant

Średnie w kolumnach oznaczone tymi samymi literami nie różnią się istotnie (test Tukeya, $\mathrm{p}=0,05$ ) - Means in columns followed by same letter do not significantly differ (Tukeys' test, $\mathrm{p}=0.05$ )

Tabela 5. Wpływu płodozmianu na stopień porażenia roślin przez chwościka buraka (C. beticola) oraz na plon i jakość korzeni (analiza kontrastu: płodozmian 2 i 3-letni vs. płodozmian 4-letni)

Table 5. Effect of crop rotation on the degree of leaf infection by leaf spot disease (C. beticola) and the yield and roots quality (contrasts analysis: 2 and 3-year crop rotation versus 4-year crop rotation)

\begin{tabular}{|c|c|c|c|c|c|c|c|c|c|c|c|c|c|}
\hline \multirow{3}{*}{$\begin{array}{l}\text { Rok } \\
\text { Year }\end{array}$} & \multicolumn{13}{|c|}{ Cecha statystyczna - Statistical feature } \\
\hline & \multirow[t]{2}{*}{$\mathrm{df}^{1}$} & \multicolumn{3}{|c|}{$\begin{array}{l}\text { stopień porażenia } \\
\text { degree of infection }\end{array}$} & \multicolumn{3}{|c|}{$\begin{array}{l}\text { plon korzeni } \\
\text { root yield }\end{array}$} & \multicolumn{3}{|c|}{$\begin{array}{l}\text { zawartość cukru } \\
\text { sugar content }\end{array}$} & \multicolumn{3}{|c|}{$\begin{array}{c}\text { plon cukru technologicznege } \\
\text { sugar yield }\end{array}$} \\
\hline & & $t^{2}$ & $\mathrm{p}^{3}$ & $d^{4}$ & $t^{2}$ & $\mathrm{p}^{3}$ & $\mathrm{~d}^{4}$ & $t^{2}$ & $\mathrm{p}^{3}$ & $d^{4}$ & $t^{2}$ & $\mathrm{p}^{3}$ & $d^{4}$ \\
\hline 2008 & 57 & 5,9 & 0,0000 & 1,6 & 16,0 & 0,0000 & 4,2 & 1,4 & 0,1746 & 0,4 & 15,2 & 0,0000 & 4,0 \\
\hline 2009 & 57 & $-1,5$ & 0,1461 & $-0,4$ & 10,4 & 0,0000 & 2,7 & 1,3 & 0,2055 & 0,3 & 9,2 & 0,0000 & 2,4 \\
\hline 2010 & 57 & 7,1 & 0,0000 & 1,9 & 11,5 & 0,0000 & 3,0 & $-4,5$ & 0,0000 & $-1,2$ & 9,2 & 0,0000 & 2,4 \\
\hline 2011 & 57 & 3,3 & 0,0019 & 0,9 & 7,3 & 0,0000 & 1,9 & 0,1 & 0,9027 & 0,0 & 7,0 & 0,0000 & 1,8 \\
\hline 2008-2011 & 237 & 4,3 & 0,0000 & 0,6 & 14,4 & 0,0000 & 1,9 & $-0,7$ & 0,4755 & $-0,1$ & 12,9 & 0,0000 & 1,7 \\
\hline
\end{tabular}

$\mathrm{df}^{1}-$ stopnie swobody - degrees of freedom, $\mathrm{t}^{2}$ - wartość statystyki testowej - value of the test statistic, $\mathrm{p}^{3}-$ prawdopodobieństwo testowe - test probability, $\mathrm{d}^{4}$ - współczynnik Cohena - Cohen's coefficient

Analiza kontrastów wykazała, że skracanie płodozmianu do rotacji 2- i 3-letniej w stosunku do rotacji 4-letniej prowadziło do istotnego wzrostu stopnia porażenia roślin przez chwościk buraka. W rotacji 2- i 3-letniej średni stopień porażenia liści przez patogena w skali $9^{\circ}$ wyniósł odpowiednio 6,3 i $6,1^{\circ}$, natomiast w płodozmianie 4-letnim $-6,8^{\circ}$. W przeliczeniu na procent porażonej powierzchni liści, według przyjętej skali, odpowiadało to około 5\% zniszczonej powierzchni liści w rotacji 2- i 3-letniej oraz $2 \% \mathrm{w}$ rotacji 4-letniej. Ponadto badania wykazały, że stopień porażenia liści przez chwościka buraka był istotnie zdeterminowany warunkami pogodowymi panującymi w roku badań. Największą presję patogena obserwowano w roku 2009 - w przybliżeniu $5^{\circ}$, a najmniejszą w $2011-\mathrm{w}$ przybliżeniu $7^{\circ}$. Największy negatywny wpływ skracania płodozmianu na stopień porażenia liści stwierdzono w roku $2010(\mathrm{~d}=1,9)$, natomiast najmniejszy w roku $2009(d=-0,4)$.

Skracanie płodozmianu miało istotny i negatywny wpływ na plon korzeni i cukru, natomiast nie oddziaływało ujemnie na zawartość cukru w korzeniach. W porównaniu do płodozmianu 4-letniego plon korzeni uzyskany w płodozmianie 2-letnim był mniejszy o $31,1 \%$, natomiast w płodozmianie 3-letnim o 18,3\%. Podobne relacje stwierdzono w plonie cukru technologicznego. Skrócenie płodozmianu do rotacji 2-letniej zmniejszyło plon cukru z hektara o 30,5\%, natomiast do rotacji 3-letniej o 17,1\%. Największe różnice w plonie korzeni i cukru w płodozmia- 
nach skróconych w stosunku do płodozmianu 4-letniego stwierdzono w roku 2008 ( $\mathrm{d}=4,2$ i 4,0), natomiast najmniejsze w roku $2011(\mathrm{~d}=1,9$ i 1,8).

\section{Wnioski / Conclusions}

1. Synteza wyników z czterech lat badań wykazała, że płodozmian był głównym czynnikiem determinującym stopień porażenia roślin przez chwościka buraka oraz wielkość plonu korzeni i cukru, natomiast nawożenie środkiem UGmax, niezależnie od wariantu, nie miało istotnego wpływu.

2. Skracanie płodozmianu do rotacji 3- i 2-letniej prowadziło do istotnego wzrostu porażenia roślin przez chwościka buraka oraz do spadku plonu korzeni i plonu cukru technologicznego.

\section{Literatura / References}

Condor A.F., Perez P.G., Lokare C. 2007. Effective Microorganisms: Myth or reality? Revista Peruana de Biología 14 (2): $315-319$.

EPPO PP 1/1(4). European and Mediterranean Plant Protection Organization. Efficacy evaluation of fungicides. Foliar diseases on sugarbeet: $1-5$.

http://www.ugmax.pl [dostęp: 25.05.2014].

Jakubus M., Kaczmarek Z., Wolna-Maruwka A. 2012. Zmiany wybranych właściwości gleby inkubowanej z dodatkiem agaru, skrobi i efektywnych mikroorganizmów. Ecological Chemistry and Engineering A 19 (1-2): 61-68.

Kucharski J., Jastrzębska E. 2005. Rola efektywnych mikroorganizmów w kształtowaniu właściwości mikrobiologicznych gleby. Inżynieria Ekologiczna 12: 295-296.

Martyniuk S. 2011. Skuteczne i nieskuteczne preparaty mikrobiologiczne stosowane w ochronie i uprawie roślin oraz rzetelne i nierzetelne metody ich oceny. Postępy Mikrobiologii 50 (4): 321-328.

Mayer J., Scheid S., Oberholzer H.R. 2008. How effective are 'Effective Microorganisms'? Results from an organic farming field experiment. 16th IFOAM Organic World Congress. Italy, Modena, June 16-20, 2008. http://orgprints.org/14838 [Accessed: 29.08.2014].

Sosnowski J. 2011. Wpływ użyźniacza glebowego i zróżnicowanych dawek azotu na wydzielanie $\mathrm{CO}_{2}$ z gleby spod uprawy Festulolium braunii z koniczyną łąkową i lucerną mieszańcową. Ochrona Środowiska i Zasobów Naturalnych 50: 52-60.

Stępień A., Pawluczuk J., Adamiak J., Marks M., Buczyński G. 2010. Wpływ wybranych czynników klimatycznych Polski północnowschodniej na jakość plonu korzeni buraka cukrowego. Fragmenta Agronomica 27 (1): 170-176.

Sulewska H., Szymańska G., Pecio A. 2009. Ocena efektów stosowania użyźniacza glebowego UGmax w uprawie kukurydzy na ziarno i kiszonkę. Journal of Research and Applications in Agricultural Engineering 54 (4): 120-124.

Trawczyński C., Bogdanowicz P. 2007. Wykorzystanie użyźniacza glebowego w aspekcie ekologicznej uprawy ziemniaka. Journal of Research and Applications in Agricultural Engineering 52 (4): 94-97.

Truba M., Jankowski K., Sosnowski J. 2012. Reakcja roślin na stosowanie preparatów biologicznych. Ochrona Środowiska i Zasobów Naturalnych 53: 41-52.

Van Vliet P.C.J., Bloem J., de Goede R.G.M. 2006. Microbial diversity, nitrogen loss and grass production after addition of effective Micro-organisms ${ }^{\circledR}(\mathrm{EM})$ to slurry manure. Applied Soil Ecology 32: 188-198.

Zarzecka K., Gugała M. 2013. Wpływ użyźniacza glebowego UGmax na plon ziemniaka i jego strukturę. Biuletyn Instytutu Hodowli i Aklimatyzacji Roślin 267: 107-111. 